\title{
A low dose of risperidone resolved Charles Bonnet syndrome after an unsuccessful trial of quetiapine: a case report
}

This article was published in the following Dove Press journal:

Neuropsychiatric Disease and Treatment

\author{
Sultan H Alamri \\ College of Medicine, King Abdulaziz \\ University, Jeddah, Kingdom of \\ Saudi Arabia
}

\begin{abstract}
Charles Bonnet syndrome (CBS) is a diagnosis of exclusion. Typical affected patients have impaired visual acuity, vivid recurring visual hallucinations, and no cognitive impairment. Vision loss is most commonly due to macular degeneration, although many other causes exist. Here, we report a case of an 87-year-old woman with CBS and discuss the diagnosis and treatment.
\end{abstract}

Keywords: Charles Bonnet syndrome, hallucinations, delusion, visual, elderly, geriatric

\section{Background}

Charles Bonnet syndrome (CBS) is characterized by the presence of visual hallucinations in patients with impaired vision. CBS is usually diagnosed in patients with significant loss of vision and no cognitive impairment. ${ }^{1,2}$ It was first described in 1,760 by the Swiss scientist and naturalist named Charles Bonnet, after talking with his 90-year-old grandfather, who experienced these symptoms. ${ }^{3}$ The term CBS was coined in 1967 by the Swiss scientist George De Morsier. ${ }^{1}$

Affected patients experience visual hallucinations that come and go without apparent reason and which can be disturbing. The hallucinations are most frequently experienced several times a day for a few minutes and consist of patterns, faces, animals, and figures, in decreasing order of frequency, which can be static or moving. These patients typically have severe ocular impairments, of which age-related macular degeneration, glaucoma, and diabetic retinopathy are the most common causes. ${ }^{4}$ Overall, CBS becomes more prevalent as the population ages with a reported prevalence between $0.4 \%$ and $39 \%$ in patients with poor vision..$^{5-7}$

This case report describes a successful response to risperidone in an 87-year-old woman with CBS after an unsuccessful trial of quetiapine. Written informed consent was obtained from the patient for the publication of this case report. No personally identifiable information was revealed in this manuscript.

\section{Case presentation}

An 87-year-old woman presented to our outpatient clinic with a 7-month history of vivid visual hallucinations. These symptoms started as simple images and sparkling lights and progressed to complex hallucinations including objects and people moving in her room. They occurred 4-6 times a day and lasted 5-10 minutes each. Although she was aware of the nature of these symptoms, the hallucinations became 
more persistent and were disturbing to her. She had good insight into her condition. There were no associated auditory hallucinations or delusions, and she had no history of any psychiatric disorder.

She denied any headaches or trauma. Her medical history included hypothyroidism and open angle glaucoma. Her medications included L-thyroxine and anti-glaucoma eye drops. Surgical history was significant for bilateral cataract surgeries a few years prior to current treatment.

Her visual acuity was $6 / 60$ in the right eye and finger counting at $1 \mathrm{~m}$ in the left eye. The scores were 6/60 in both eyes 2 years prior to her presentation. Mental status examination revealed an appropriately dressed woman with no psychomotor agitation or retardation. Her thoughts were logical and goal directed. Affect was euthymic with spontaneous emotional reactivity. Mini-Mental State Examination revealed normal cognitive function including normal orientation and intact recall and attention abilities.

Laboratory tests included a normal complete blood count, blood sugar, kidney and liver function, thyroid stimulating hormone, vitamin B12, and calcium levels. Magnetic resonance imaging of the brain revealed age-related atrophic changes with small vessel disease.

The diagnosis of typical CBS was made based on the presence of visual hallucinations with visual impairment in a cognitively normal patient without psychiatric illness. The patient was initially treated with quetiapine $25 \mathrm{mg} /$ day, which was later increased to $50 \mathrm{mg} /$ day. After $1 \mathrm{month}$, the hallucinations were still present, and the patient was distressed. Hence, the treatment was changed to risperidone, $0.5 \mathrm{mg} /$ day. After 3 days, the patient had cessation of the visual hallucinations lasting until her next visit, 6 weeks later. The patient's risperidone was then decreased to $0.25 \mathrm{mg} /$ day; however, the hallucinations reoccurred. The dose was then returned to $0.5 \mathrm{mg} / \mathrm{day}$, and the hallucinations disappeared again.

\section{Discussion}

The diagnosis of CBS is one of exclusion. Affected patients should be evaluated to exclude organic brain disorders, dementia, substance abuse, schizophrenia, and mood disorders. ${ }^{8}$ Evaluation should include a complete history, physical examination, and mental state examination. A team approach including psychiatry, neurology, and ophthalmology is best used to diagnose CBS.

CBS has been explained as a visual disorder in persons with visual loss where the brain tries to fill in gaps in their loss of vision. ${ }^{9}$ Patients who do not understand the nature of their disease may be frightened and require supportive treatment. They should be reassured the hallucinations are not a mental disorder and can be a common consequence of their ocular disease. ${ }^{3}$ They can also benefit from participation in support groups consisting of affected individuals. ${ }^{10}$ Treatment of the visual disorder in patients with typical CBS may impact the frequency of hallucinations and improve quality of life. ${ }^{11}$

The visual cortex, when deprived of visual stimulation, has significantly lower serotonin levels than in the normal state. ${ }^{12}$ Dopamine and acetylcholine are other neural transmitters thought to be involved in the formation of visual hallucinations. ${ }^{13}$ Experience with medical treatment to correct these levels is limited, and the reported cases demonstrated short follow-up results. Overall, the number of patients treated pharmacologically is small, and there is no consensus on best medical treatment. Psychotropic medications such as anti-depressants, anxiolytics, antipsychotics, and anticonvulsants have been used to treat hallucinations associated with CBS with varied results..$^{3,8,10,14}$ Serotonin reuptake inhibitors (SSRIs) can inhibit the activity of neurons in the occipital lobe related to the occurrence of visual hallucinations. ${ }^{3}$ Antipsychotics such as haloperidol, olanzapine, and risperidone are thought to act by blocking serotonin and dopamine receptors. ${ }^{3}$ The patient's visual hallucinations did not improve with a trial of quetiapine, but responded to a low dose of risperidone. A small number of reports show improvement in visual hallucinations with risperidone and olanzapine. ${ }^{13,15,16}$ The reduced efficacy of quetiapine compared to other atypical antipsychotics has been reported in a recent systematic review. ${ }^{17}$ Although there has been no standard treatment so far, anecdotal evidence seemed to favor antipsychotics and SSRIs as possible treatment options for the disturbing hallucinations associated with $\mathrm{CBS} .^{3,8,10,14}$

\section{Conclusion}

CBS is characterized by visual hallucinations in cognitively intact individuals. Most affected individuals have impaired vision, usually with macular degeneration. Most patients require only reassurance. When possible, treatment of the underlying visual disorder might lead to reduction or disappearance of hallucinatory phenomena. In more severe and disturbing cases, pharmacological treatment is required. Case reports or case series on the topic or even small trials, possibly with a longer follow-up duration, are still needed to define best treatment.

\section{Disclosure}

The author reports no conflicts of interest in this work. 


\section{References}

1. De Morsier G. Les hallucinations visuelles diencéphaliques. Deuxième partie. Psychiatr Clin. 1969;2(4):232-251.

2. Jacob A, Prasad S, Boggild M, Chandratre S. Charles Bonnet syndromeelderly people and visual hallucinations. BMJ. 2004;328(7455): $1552-1554$.

3. Pang L. Hallucinations experienced by visually impaired: Charles Bonnet syndrome. Optom Vis Sci. 2016;93(12):1466-1478.

4. Gordon KD. Prevalence of visual hallucinations in a national low vision client population. Can J Ophthalmol. 2016;51(1):3-6.

5. Tan C, Lim V, Ho D, Yeo E, Ng B, Eong KA. Charles Bonnet syndrome in Asian patients in a tertiary ophthalmic centre. Br J Ophthalmol. 2004; 88(10):1325-1329.

6. Singh A, Sørensen TL. The prevalence and clinical characteristics of Charles Bonnet Syndrome in Danish patients with neovascular agerelated macular degeneration. Acta Ophthalmol. 2012;90(5):476-480.

7. Cox TM, Ffytche DH. Negative outcome Charles Bonnet syndrome. Br J Ophthalmol. 2014;98(9):1236-1239.

8. Jackson ML, Ferencz J. Charles Bonnet syndrome: visual loss and hallucinations. Can Med Assoc J. 2009;181(3-4):175-176.

9. Kazui H, Ishii R, Yoshida T, et al. Neuroimaging studies in patients with Charles Bonnet Syndrome. Psychogeriatrics. 2009;9(2):77-84.
10. Eperjesi F, Akbarali N. Rehabilitation in Charles Bonnet syndrome: a review of treatment options. Clin Exp Optom. 2004;87(3):149-152.

11. Yacoub R, Ferrucci S. Charles Bonnet syndrome. Optometry. 2011; 82(7):421-427.

12. Lang UE, Stogowski D, Schulze D, et al. Charles Bonnet Syndrome: successful treatment of visual hallucinations due to vision loss with selective serotonin reuptake inhibitors. J Psychopharmacol. 2007;21(5): 553-555.

13. Moja MC, Milano E, Gasverde S, Gianelli M, Giordana M. Olanzapine therapy in hallucinatory visions related to Bonnet syndrome. Neurol Sci. 2005;26(3):168-170.

14. O'Farrell L, Lewis S, McKenzie A, Jones L. Charles Bonnet syndrome: a review of the literature. J Vis Impair Blind. 2010;104(5):261-274.

15. Howard R, Meehan O, Powell R, Mellers J. Successful treatment of Charles Bonnet syndrome type visual hallucinosis with low-dose risperidone. Int J Geriatr Psychiatry. 1994;9:9677-9678.

16. Thorpe L. The treatment of psychotic disorders in late life. Can J Psychiatry. 1997;42 Suppl 1:19S-27S.

17. Asmal L, Flegar SJ, Wang J, Rummel-Kluge C, Komossa K, Leucht S. Quetiapine versus other atypical antipsychotics for schizophrenia Cochrane Database Syst Rev. 2013;(11):CD006625.
Neuropsychiatric Disease and Treatment

\section{Publish your work in this journal}

Neuropsychiatric Disease and Treatment is an international, peerreviewed journal of clinical therapeutics and pharmacology focusing on concise rapid reporting of clinical or pre-clinical studies on a range of neuropsychiatric and neurological disorders. This journal is indexed on PubMed Central, the 'PsycINFO' database and CAS,

\section{Dovepress}

and is the official journal of The International Neuropsychiatric Association (INA). The manuscript management system is completely online and includes a very quick and fair peer-review system, which is all easy to use. Visit http://www.dovepress.com/testimonials.php to read real quotes from published authors. 